\title{
Seminar penyuluhan Napza bersama Karangtaruna Taruna Jaya Trotok, Wedi, Klaten
}

\author{
Eko Wiratno $^{1)} \mid$ Muhammad Aga Sekamdo $^{2)} \mid$ Dwi Suci Lestariana $^{3)}$ \\ ${ }^{1,2)}$ Sekolah Tinggi Ilmu Administrasi Madani, ${ }^{3}$ Universitas Boyolali \\ ekowiratno@stiamadani.ac.id
}

\begin{abstract}
Abstrak: Narkotika dan Obat-obatan Terlarang yang disingkat Narkoba menjadi permasalahan yang harus segera ditumpas dan diselesaikan di Indonesia secepat mungkin. Narkotika, Alkohol, Psikotropika dan Zat Adiktif disingkat NAPZA merupakan barang terlarang dan berbahaya bagi para pemakainya, barang ini sudah menjadi trend dikalangan generasi muda. Berdasarkan hasil survei Badan Narkotika Nasional (BNN) dan Lembaga Ilmu Pengetahuan (LIPI) angka penyalahgunaan NAPZA di Indonesia pada tahun 2019 mencapai 3.419.188 yang berumur 15-64 tahun dan sebuah angka yang fantastis. Hasil akhir dari pengabdian kepada masyarakat ini diharapkan dapat memberikan manfaat pada mitra yang digandeng dalam hal ini pemuda-pemudi yang tergabung dalam wadah Karang Taruna "Taruna Jaya" di Desa Trotok, Kecamatan Wedi, Kabupaten Klaten untuk memiliki pengetahuan tentang NAPZA secara komprehensif dan dapat meningkatkan kesadaran pengurus dan anggota Karang Taruna untuk menjahui narkoba. Metode yang digunakan dalam pengabdian kali ini antara lain dengan metode ceramah, diskusi, tanya jawab dan evaluasi kegiatan untuk mengetahui sejauh mana pengetahuan para peserta setelah mengikuti kegiatan ini. Terdapat peningkatan pengetahuan tantang NAPZA pada Karangtaruna Desa Trotok, Kecamatan Wedi, Kabupaten Klaten sebagai upaya dalam pencegahan penyalahgunaan obat-obatan yang dapat merusak kesehatan fisik dan jiwa dan jelas melanggar norma agama dan norma susila
\end{abstract}

Kata Kunci: penyuluhan, NAPZA, karangtaruna, pencegahan penyalahgunaan obat

\section{Pendahuluan}

Visi dan misi dari pembangunan nasional Indonesia yaitu mewujudkan manusia Indonesia yang utuh dan masyarakat Indonesia yang menyeluruh tanpa membedakan Suku, Agama, Ras, Pulau menuju masyarakat yang adil, makmur, sejahtera dan damai berdasarkan Pancasila dan Undang-Undang Dasar 1945. Dalam perwujudan masyarakat Indonesia yang sejahtera, maju tersebut perlu adanya peningkatan secara terus-menerus di bidang pengobatan dan pelayanan disektor kesehatan di Indonesia termasuk ketersediaan narkoba sebagai obat, di samping untuk usaha pengembangan ilmu pengetahuan yang meliputi penelitian, pengembangan, pendidikan, dan pengajaran sehingga ketersediaannya perlu melalui kegiatan produksi dan impor.

Pembangunan disektor kesehatan sebagai bagian integral dari pembangunan nasional diarahkan demi tercapainya kesadaran, kemauan dan kemampuan hidup sehat bagi setiap penduduk agar dapat mewujudkan derajat kesehatan yang optimal dan maksimal, yang dilakukan melalui berbagai upaya kesehatan, di antaranya penyelenggaraan pelayanan kesehatan kepada masyarakat. Meskipun narkoba sangat diperlukan untuk pengobatan dan pelayanan kesehatan, namun bila disalahgunakan atau digunakan tidak sesuai dengan standar pengobatan, terlebih jika disertai dengan peredaran narkoba secara gelap dan masif serta ilegal akan menimbulkan akibat yang sangat merugikan perorangan ataupun masyarakat, khususnya generasi muda Indonesia.

Maraknya pemakaian narkoba di luar indikasi medik, tanpa petunjuk atau resep dokter, dan pemakaiannya bersifat patologik (menimbulkan kelainan) dan menimbulkan hambatan dalam aktivitas di rumah, sekolah atau kampus, tempat kerja dan lingkungan sosial. Ketergantungan narkoba diakibatkan oleh penyalahgunaan zat yang disertai dengan adanya toleransi zat dan gejala putus asa, yang memiliki sifat-sifat keinginan yang tak tertahankan, kecenderungan untuk menambah dosis, 
ketergantungan fisik dan psikologis. World Drugs Reports 2018 yang diterbitkan United Nations Office on Drugs and Crime (UNODC), menyebutkan sebanyak 275 juta penduduk di dunia atau 5,6 \% dari penduduk dunia (usia 15-64 tahun) pernah mengkonsumsi narkoba.

Menurut badan dunia bidang kesehatan World Health Organization (WHO) pengguna NAPZA di penjuru dunia mencapai 190 juta orang. Sementara pengguna NAPZA di Indonesia cenderung mengalami peningkatan dari tahun ke tahun (Rachmawati \& Suryawati, 2018). Menurut Mayer et al (2009) penyalahgunaan NAPZA yaitu masalah kesehatan publik yang penting dimana secara langsung akan berdampak pada ekonomi, kesehatan dan juga sosial.

Data BNN menyebutkan juga rata-rata 50 orang meninggal karena narkoba setiap harinya yang berarti sekitar 18.000 orang setiap tahunnya dan menurut hasil survey BNN mendapatkan temuan bahwa $24 \%$ pengguna NAPZA adalah remaja. Menurut data survei dari Badan Narkotika Nasional (BNN) pusat dengan angka prevalensi 2,2 atau mencapai 53,177 jiwa penggunanya (Kementerian Kesehatan RI, 2014).Narkoba mempunyai dampak negatif yang sangat luas ; baik secara fisik, psikis, ekonomi, sosial, budaya, hankam, dan lain sebagainya. Bila penyalahgunaan narkoba tidak diantisipasi dengan baik, maka akan rusak bangsa dan negara ini. Oleh karena itu, diperlukan kerja sama yang baik dari seluruh komponen bangsa untuk penanggulangan penyalahgunaan narkoba. (Soedjono, 2000)

Tujuan diberikan penyuluhan pada mitra yang dalam hal ini adalah Karang Taruna Desa Trotok, Kecamatan Wedi, Kabupaten Klaten agar mampu memahami NAPZA dan dapat menghindari untuk mengkonsumsinya serta menurunkan angka kejadian penyalahgunaan konsumsi obat-obatan terlarang ini. Sehingga remaja dapat hidup dengan sehat, karena remaja yang sehat merupakan remaja yang bebas dari narkoba dan negara akan kuat. Penyalahgunaan NAPZA adalah penggunaan NAPZA yang digunakan bukan untuk tujuan pengobatan dengan jumlah berlebih, teratur dan berlangsung cukup lama, sehingga menyebabkan gangguan kesehatan fisik serta gangguan pada perilaku dan kehidupan sosialnya (Martono dan Joewana, 2008).

\section{Hasil}

Kegiatan penyuluhan ini dilaksanakan di aula Desa Trotok, Kecamatan Wedi, Kabupaten Klaten, Provinsi Jawa Tengah. Mitra merupakan organisasi Karangtaruna Desa Trotok yang berjumlah 25 peserta.Remaja merupakan indidvidu yang sedang mengalami masa perubahan pada semua aspek dalam dirinya, yaitu perubahan dari kondisi anak-anak menuju dewasa. Remaja adalah mereka yang berada pada usia 12-18 tahun (Hasibuan, 2011). Perkembangan remaja sangat rentan terhadap pengaruh dari lingkungan dalam kehidupan sehari-hari

Metode yang disampaikan dengan learning by doing. Transfer kegiatan melalui penyuluhan dan pelatihan menggunakan media power point, leaflet, audio visual. Metode yang dipakai antaralain dengan ceramah, tanya jawab, diskusi dan penayangan video. Tahapan kegiatan dimulai dengan icebraking, pretest, penyampaian materi, dan ditutup dengan post-test.

Evaluasi kegiatan ini dengan maksud untuk mengukur tingkat keberhasilan dari program yang ditawarkan, yang meliputi evaluasi pengetahuan dan pemahaman (knowledge) yang pelaksanaanya dengan cara pretest dan posttest kepada seluruh peserta (Riani \& Ambarwati, 2020). Media yang digunakan dalam penyuluhan berupa leaflet dan materinya berbentuk power point.

Selama kegiatan berlangsung, para peserta yang mayoritas berusia 20-40 tahun ini sangat aktif dan banyak bertanya terkait hal-hal yang belum dipahaminya. Diskusi dan tanya jawab didampingi oleh Tim pengabdian. Selama pemberian materi berlangsung, peserta aktif berpartisipasi dan bertanya hal-hal yang tidak dipahami. Proses diskusi membahas berbagai hal yang berkaitan dengan NAPZA. Kegiatan ini diakhiri dengan pemberian posttest sebagai hasil evaluasi pemberian penyuluhan.

Kegiatan penyuluhan NAPZA terdiri dari tahapan sebagai berikut:

a. Pretest

Dengan tujuan untuk mengetahui kemampuan setiap peserta sebelum mengikuti kegiatan. Peserta diberikan soal terkait NAPZA. Alokasi waktu yang diberikan adalah 15 menit. Nilai peserta yang didapatkan rata-rata 60 yang artinya cukup. 
b. Penyampaian Materi

Materi yang disampaikan terdiri dari materi NAPZA. Alokasi waktu yang diberikan adalah 60 menit dan dilanjutkan dengan diskusi dan tanya jawab.

c. Posttest

Posttest dilaksanakan di akhir kegiatan untuk mengetahui kemampuan peserta di akhir kegiatan setelah para peserta selesai mengikuti kegiatan semua. Hasil posttest menunjukan adanya peningkatan pengetahuan peserta dengan nilai rata rata 60 menjadi 90, yang artinya para peserta memahami apa yang disampaikan Tim pengabdian masyarakat terjadi peningkatan yang signifikan.
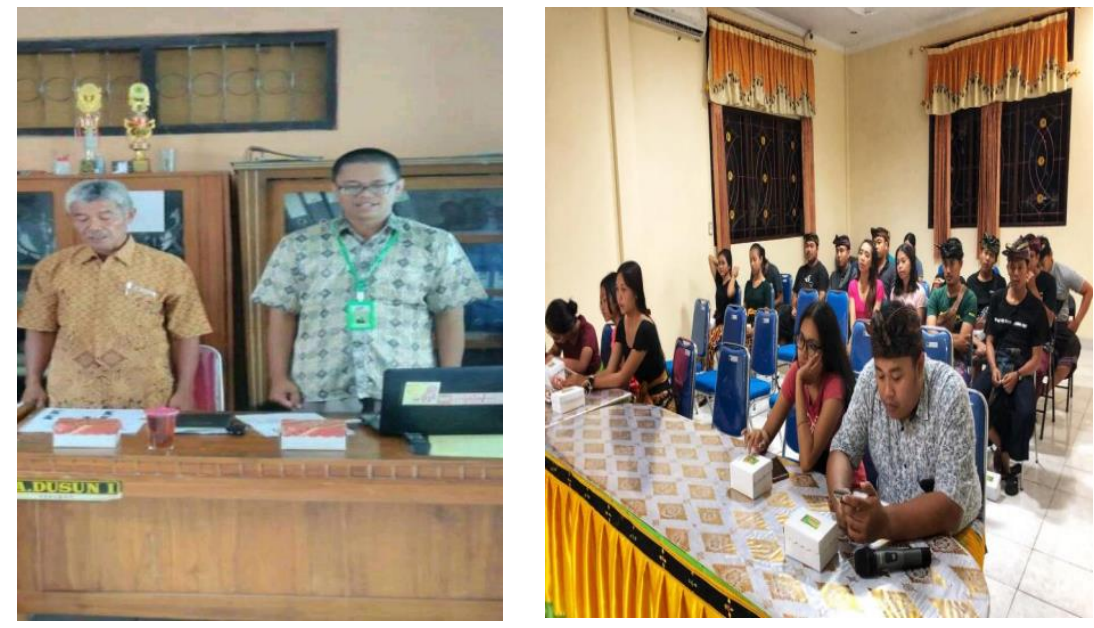

Gambar 1. Pembukaan dan Penyuluhan Pengabdian Masyarakat.

\section{Kesimpulan}

Terdapat peningkatan pengetahuan tentang NAPZA pada Pengurus dan anggota Karangtaruna "Taruna Jaya" Desa Trotok, Kecamatan Wedi, Kabupaten Klaten, Jawa Tengah upaya dalam pencegahan penyalahgunaan obat-obatan yang dapat merusak kesehatan fisik dan jiwa. Setiap pecandu narkoba setiap saat membutuhkan narkotika sebagai bagian dari kebutuhan hidupnya yang cenderung dosisnya akan selalu bertambah, dibandingkan dengan dengan beberapa barang dagangan lainnya, narkotika adalah komoditi yang menguntungkan, meskipun ancaman dan resikonya cukup berat.(Sitanggang, 1999). Karangtaruna akan ikut berperan aktif dalam kegiatan desa guna menurunkan angka kejadian penyalahgunaan obat-obatan.

\section{Daftar Pustaka}

Martono, L. H., \& Joewana, S. (2006). MEMBANTU PEMULIHAN PECANDU NARKOBA DAN KELUARGANYA. Jakarta: Balai Pustaka.

Maeyer, J.D., Wouter, V., Eric, B. (2009). Exploratory Study on Drug Users' Perspectives on Quality of Life: More than Health-Related Quality of Life?. soc Indic Res (2009) 90:107-126 retrivied DOI 10.1007/s1125-008-9315- 7.

Riani, E. N., \& Ambarwati, D. (2020). Early Detection Kanker Serviks Sebagai Upaya Peningkatan Derajat Hidup Perempuan. SELAPARANG Jurnal Pengabdian Masyarakat Berkemajuan, 3(2), 144. https://doi.org/10.31764/jpmb.v3i2.1883

Riani, E. N., Shaluhiyah, Z., \& Widagdo, L. (2016). Petugas Lapangan Sebagai Ujung Tombak Jumlah Pengunjung Klinik VCT. Jurnal Promosi Kesehatan Indonesia, 9(2), $152-$ 161. https://doi.org/10.14710/jpki.9.2.152-161 
Rachmawati, S., Suryawati, S., \& Rustamaji, R. (2018). Efektivitas CBIA-Narkoba dalam Peningkatan Pengetahuan Remaja untuk Menolak Narkoba. Media Kesehatan Masyarakat Indonesia, 14(4), 339-344. Retrieved from

https://journal.unhas.ac.id/index.php/mkmi/article/view/4477

Sitanggang, B.A, 1999, Pendidikan Pencegahan Penyalahgunaan Narkotika, Jakarta, Karya Utama

A. Soedjono, 2000, Patologi Sosial, Bandung, Alumni

https://fin.co.id/2021/06/28/pengguna-narkoba-di-indonesia-capai-34-juta-orang. Di Unduh 6 Agustus 2021 